\title{
Towards a unifying visualization modelling platform for supporting climate change conscious urban neighbourhood design
}

\author{
Amr Elwan ${ }^{1,2}$, Chengzhi Peng ${ }^{1}$, Mohammad Fahmy ${ }^{2}$ \\ ${ }^{1}$ School of Architecture, University of Sheffield, Sheffield, UK \\ ${ }^{2}$ Department of Architecture, Military Technical College, Cairo, Egypt \\ *Corresponding author. Tel: +447578409402, Fax: +441142220315, E-mail: a.elwan@sheffield.ac.uk
}

\begin{abstract}
Urban physical environments will face up to the challenges posed by global climate change. Various software packages for urban environmental simulation have been created to aid predictions of design performance under climate change conditions as understood today. However, the outputs from these simulation packages present great difficulties for planners, architects and urban designers working in urban neighbourhood projects. Furthermore, designers lack proper tools to bring the outdoor and indoor simulation results together to form an integrated picture at the urban neighbourhood level. It is vital that designers are enabled to achieve such a holistic understanding of their design consequences simply because those indoor and outdoor environments are constantly interconnected with each other. This paper presents this pilot study on setting up an environmental visualization methodology of global climate change at a local scale and how it can be applied to a real urban neighbourhood development project proposed for a site in the City of Cairo, Egypt. The result shows an initial step of addressing the urgent need for a practical visualization modelling platform accessible to urban designers, architects, and decision makers towards sustainable urban forms.
\end{abstract}

Keywords: Urban neighbourhood, Outdoor-indoor climate coupling, Sustainable urban neighborhood developments.

\section{Introduction}

Urban climatology is an interdisciplinary field related to urban form design. Its complexities have prevented applying climate knowledge within the urban planning process and practice (Oke 1984; Eliasson 2000; Ali-Toudert, Djenane et al. 2005; Oke 2006; Ali-Toudert and Mayer 2007b; Fahmy and Sharples 2008b; Fahmy 2010a).Recently the challenges posed by global climate change have attracted intense research attention world-wide (McEVOY 2007; Levermore 2008; Fahmy 2010a). Due to the long shelf-life of carbon dioxide in the atmosphere, much of the climate change over the coming decades has already been determined by historic emissions (Hulme, Lu et al. 2002). Additionally statistics show that urban environments caused $75 \%$ of pollution and 20 percent of carbon dioxide emissions is caused by transport which constitutes 50\% of global warming (Barton 1995 and Levermore 2008). Scientists believe that greenhouse gas concentration is increasing global warming(Radhi 2009).Climate change, and increasing urbanisation will mean that, for the rest of this century, urban thermal comfort will become an increasingly important issue for many city residents. The increased use of air conditioning is not available as a long term solution as it will, not only discharge more waste heat into the urban environment, but will also add to CO2 emissions (Fahmy and Sharples 2010b).

Oke (1999) highlighted the meteorological locations and their importance on urban microclimate, this means a weather data files (WDF) of typical meteorological years is measured at weather stations. WDF is used for indoor and outdoor thermal performance simulations by many models either in their EPW, WEA, EPS-r formats to provide hourly data of the whole year or a STAT format to provide an averaged hourly data of the months (DOE, 2009; Radhi, 2009 and Fahmy et al., 2009). This hourly WDF contains the different measured hourly meteorology for a specific location extracted from 30 years ago. WDF represents meteorological parameters e.g. dry bulb temperature, wet bulb temperature, relative humidity, 
Specific humidity, direct normal radiation, diffuse horizontal radiation, and global horizontal radiation illuminance.

The intergovernmental panel for climate change (IPCC) has recently drawn attention to the significant warming of capital cities across the world. Understanding the influence of the emissions on air quality motivates the planners to use near-term scenarios. "Near-term adaptation and mitigation analyses can be matched to conventional planning time scales, can explore opportunities and constraints given institutional and technological inertia, and can play an important role in integrating climate change considerations into other areas of management and policy."(IPCC 2007). There are several methods capable of creating near-term scenarios of climate change. One of these methods is weather data morphing methodology which manipulates historical weather data for climate scenarios. This will be provided by Climate Change World Weather File Generator, which generates future WDF for 2050(IPCC 2010).

In this research, ENVI-met 3.1 simulation software is used to relocate the measured EnergyPlus Weather (EPW), and generate an accurate WDF. Furthermore, ENVI-met 3.1 takes into consideration the influence of urban neighbourhood elements e.g. buildings, soil, vegetation, and trees. Finally, the generated WDF is used in CC World Weather Gen Tool and ECOTECT 2011. Simulation method is important to visualize the effect of outdoor thermal environment on indoor environment(He, Hoyano et al. 2009). Therefore this paper aims to assess the potential of this methodology in a pilot study, which supports climate change conscious urban neighbourhood design.

\subsection{Methodology}

The outdoor assessment of urban form is carried out by using the numerical model ENVI-met, which simulates the microclimatic changes within urban environments. The relationship between buildings and urban climate can be understood through the connection between indoor and outdoor thermal, comfort which have shared issues (coupling methodology)(AliToudert and Mayer 2006). The relationship between buildings and urban climate can be understood through the numerical coupling methodology. that connects between indoor and outdoor thermal performances (Fahmy et al., 2009).

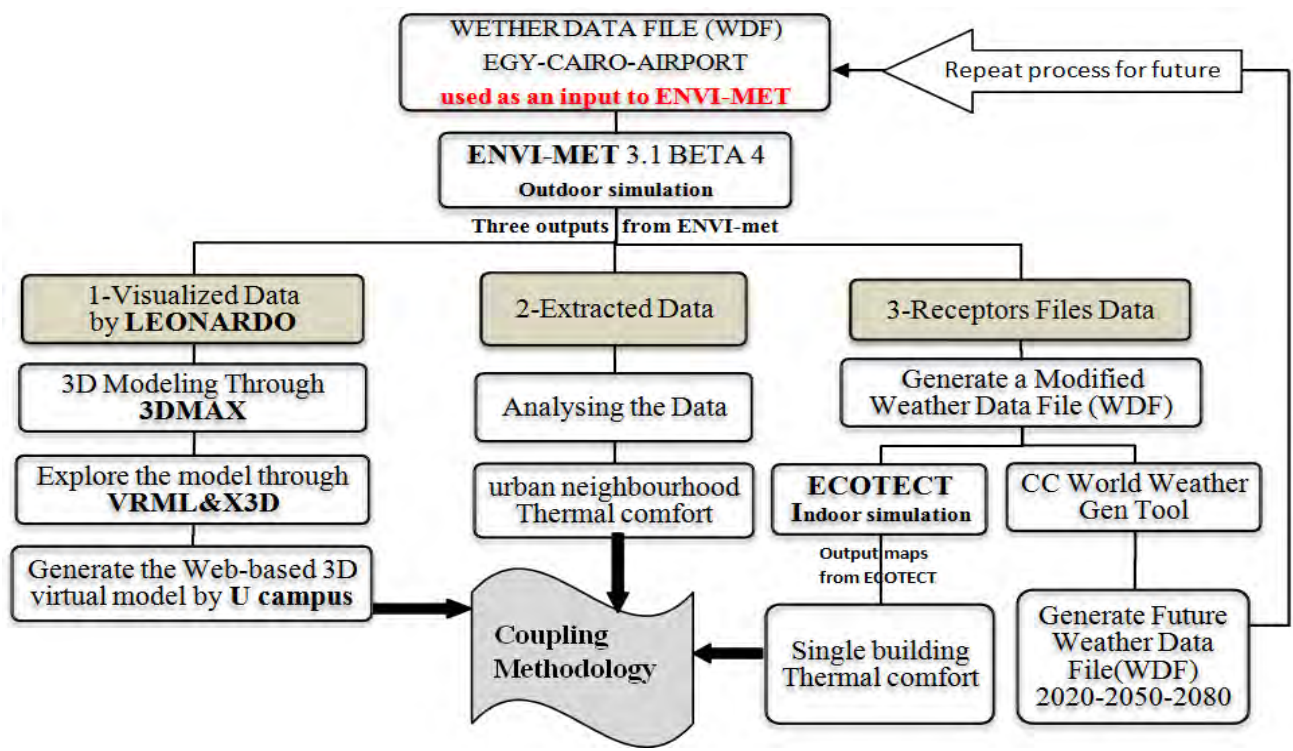

Fig.1. Methodology process based on WDF of present day and future.

The methodology has been carried out in four stages (Fig.1): Firstly, the outdoor simulation of an urban neighbourhood by numerical modeling to obtain present day outdoor meteorological 
data which in turn affects the neighbourhood indoor conditions. ENVI-met 3.1 BETA4 is used to generate fine-tuned meteorological parameters at different heights of a building unit by placing snapshot receptors around the unit to obtain the near walls present day climate conditions for the building. Secondly, for the indoor simulation and thermal analyses of the prototypes residential clusters, ECOTECT 2011 is used for its computability with the various used software packages. ECOTECT uses EnergyPlus as a core for the calculation of thermal interactions in a specific location using EnergyPlus Weather data file, EPW. Cairo's EPW file is compiled from about 30 years of meteorological measurements in Cairo International Airport weather station, which ENVI-met results were added to the urban settings effects and represented in a new EPW file, fig.1.Thirdly, given the outdoor-indoor coupled simulations performed on a common set of meteorological parameters. We can plot (a) outdoor ground contoured maps for thermal comfort extracted from ENVI-met, and (b) multiple indoor thermal profiles along the building unit compartments using ECOTECT. Finally, a Webbased 3D virtual model of the entire urban neighbourhood is built to insert both the ENVI-met outdoor mapping and ECOTECT indoor profiling results. Viewers are thus able to perceive the combined results from (a) and (b) via interactive navigation through the 3D virtual urban neighbourhood. These simulations software can be used to calculate and assess comparative environmental impacts by 3D master planning of urban form. This can be applied to present and future weather by generating morphed data to be used with building performance simulation. Eventually, for an executable regeneration policy, such 3D illustrations can be accessed over the Web to support both policy and decision makers for further investigations to avoid the negative impact due to the future global warming by upgrading and regenerating urban forms. For the preparation of a morphed weather data files in the Energy Plus format, CCWorldWeatherGen1.4 will be used and the previous steps for the new future weather data file will be repeated. (CCWorldWeatherGen 2010).

\section{Case study description}

Due to the expected large area of a selected case study, field work including measurements is not a suitable method of assessment for the existing situation. Particularly, the simulation process will be repeated many times with different conditions. The selected Case study is in a new compound development at the east of the existing old city in Cairo. The new development is an ongoing project held by DAMAK Company, fig.2. The master plan contains repeated prototypes which consist of 3 floors. Four single semidetached building units in different locations in the neighbourhood were chosen, Table1.

Table1. Detailed model description of the case study.

\begin{tabular}{|c|c|c|}
\hline Parameter & Detailed model $(1,2)$ & Detailed model $(3,4)$ \\
\hline Total area & $540 \mathrm{~m} 2$ & $500 \mathrm{~m} 2$ \\
\hline No. of floor & 3 floors & 3 floors \\
\hline Ext. walls & $0.25 \mathrm{~m}$ brick $20 \mathrm{~mm}$ plaster inside & $0.25 \mathrm{~m}$ brick $20 \mathrm{~mm}$ plaster inside \\
\hline Int.walls & $0.25 \mathrm{~m}$ brick $20 \mathrm{~mm}$ plaster inside & $0.25 \mathrm{~m}$ brick $20 \mathrm{~mm}$ plaster inside \\
\hline Floor height & $3.2 \mathrm{~m}$ & $3.2 \mathrm{~m}$ \\
\hline Orientation & North to south & East to west \\
\hline Roof & $\begin{array}{c}20 \text { tiles } 20 \text { mortar } 50 \text { sand } 150 \mathrm{~mm} \\
\text { concert }\end{array}$ & $\begin{array}{c}20 \text { tiles } 20 \text { mortar } 50 \text { sand } 150 \mathrm{~mm} \\
\text { concert }\end{array}$ \\
\hline Glazing & $6 \mathrm{~mm}$ single glass & $6 \mathrm{~mm}$ single glass \\
\hline Thermal zones & Multi zones & Multi zones \\
\hline
\end{tabular}




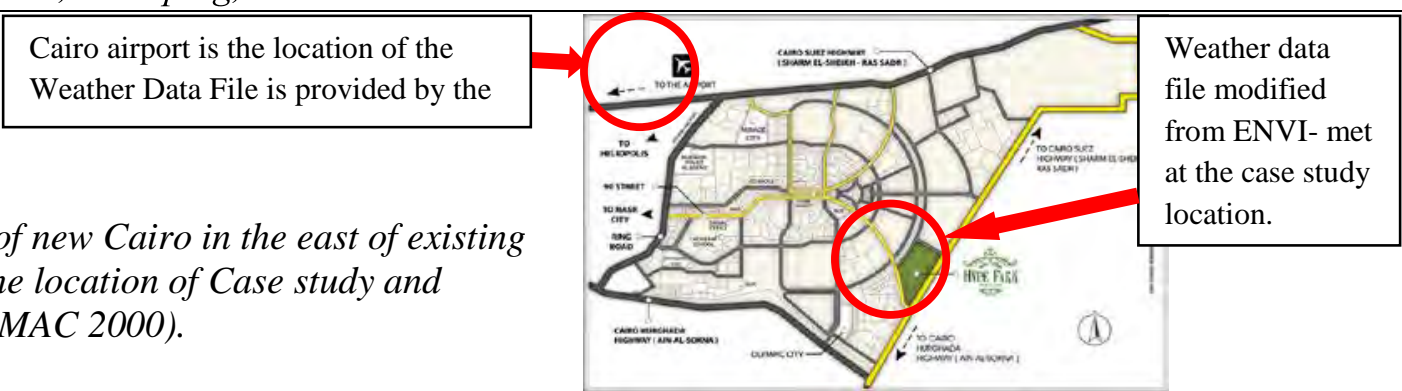

Fig.2.map of new Cairo in the east of existing old town, the location of Case study and airport(DAMAC 2000).

\section{Results and analyses}

Scenarios use simple models to measure the existing climate projections. This gives comparable results to the full three dimensional climate models. There are limitations of these scenarios; Firstly, the scenarios should not be considered forecasts or predictions, but representative scenarios. Secondly, these scenarios support scientific research to test their implication for adaptation and mitigation. Thirdly, there are uncertainties about using future scenarios particularly for emissions profiles. There are new techniques are developed for translating emissions and uncertainty analyses.(IPCC 2007)In this respect the morphing methodology used in CC World Weather Gen, which might include uncertainties due to wind information unchanged, but other modified meteorological parameter in the new WDF provide an acceptable level of knowledge (McEvoy 2007). Another sort of uncertainties can be expected through the applied software cycle by feeding the tool output to another with a converted file extension between them. However, there was no other way to check such methodology, because all models in literature visualize separately both outdoor and indoor simulation. In addition, architects, and planners need to communicate this software process for climate knowledge. This might height the gap between outdoor and indoor invironmental simulation software.

\subsection{Outdoor simulation}

The three dimensional model ENVI-met 3.1 BETA4 was chosen to simulate comfort quantities and the meteorological factors within an urban microclimate model. Our three dimensional model ENVI-met requires a few input parameters which are entered to a configuration file. Whenever the simulation starts to calculate the meteorological factors e.g.

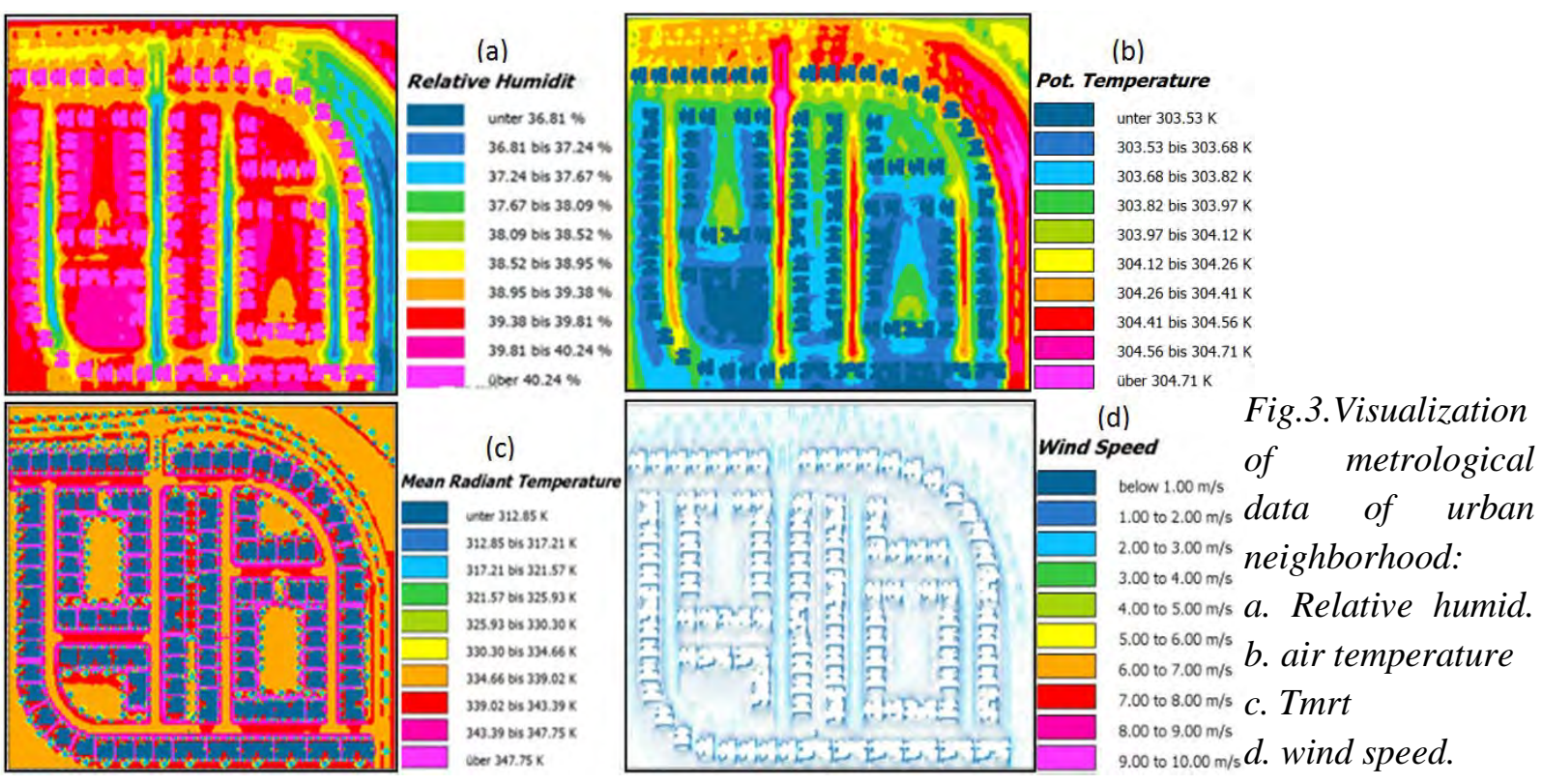


wind speed and direction, air and surface temperature, air humidity, short- wave and longwave radiation fluxes, in addition to the mean radiant temperature which is needed for comfort analyses. The Simulation date was on $1^{\text {st }}$ of June, because it is the typical summer day and started at peak time from 10:00 to 1600. After the simulation finished by 3D numerical model ENVI-met 3.1 Beta 4, we had three outputs: firstly, the maps which illustrate the different metrological factors by colors; secondly, receptors file which are used to generate an accurate WDF instead of the one provided by the USDOE, which was measured at the Cairo Airport, about $30 \mathrm{~km}$ away from the study site; and finally, extracted data for every hour of the simulation, fig.3.

As can see in Fig.3, there is a higher temperature at outer and inner roads. Wind speed at the outer roads is higher than the inner roads because wind direction is blocked by the buildings. Additionally, specific and relative humidity are lower inside the neighbourhood. This will lead to a lower mean radiant temperature. Eventually all the previous conditions will affect pedestrians' thermal comfort. The comparison among the meteorological data influences the thermal comfort of the urban neighbourhood, therefore air temperature, specific humidity, wind speed, relative humidity and mean radiant temperature are the parameters which control the urban neighbourhood thermal comfort.

\subsection{Indoor simulation}

Four housing units in different locations of the neighbourhood were selected and the closed thermal zones of every model inside ECOTECT 2011 built. The provided weather data file by ENVI-met used into the simulation. Eventually, the detailed model built by 3D MAX in separated floors and the resulted thermal maps by ECOTECT attached into the model, fig. 4 .

\subsection{Coupling outdoor and indoor}

Outdoor and indoor simulations are held and followed by 3DMAX to collect the different results in a rendered thematic model with a detailed terrain and elements of microclimate, (Fig.4). Then the models were grouped into different categories. E.g. group 1 contains the urban terrain and separated floors of the detailed modes, group 2 for the ENVI-met outdoor simulations and group 3 for ECOTECT indoor simulations. Finally, a Web-based 3D virtual model of the entire urban neighbourhood was built through VRML, X3D and made available on the web via the uCampus platform (Peng and Blundell Jones 2004).

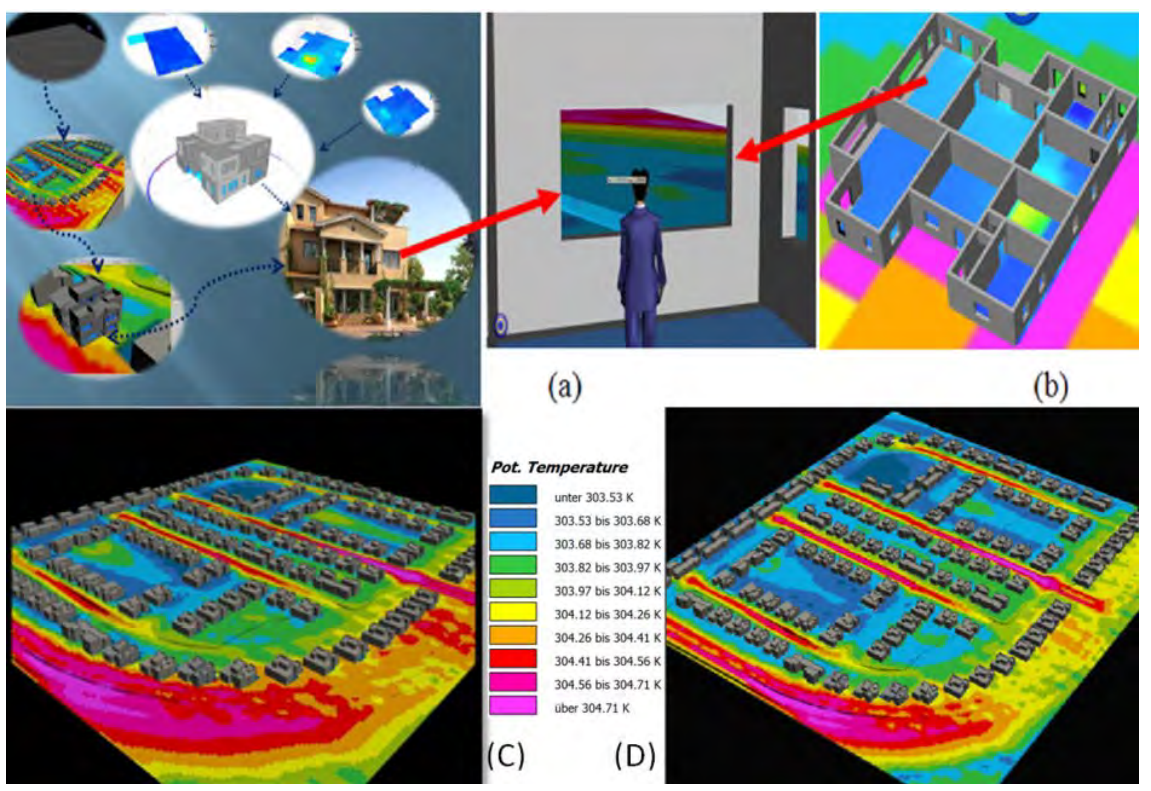

Fig.4 Bring outdoor and indoor simulation together (a) \& (b) illustrate the $3 D$ virtual model.(c)Air temperature predicted by the morphed 2050 scenario and (d) Air Temperature of present day.(c) and (d) illustrate the difference in temperature, not only at inner roads, but also at all spatial urban canyons, due to the increase in air temperature in the 2050. 
Following the work of Fahmy et al., (Fahmy, Trabolsi et al. 2009), as ENVI-met does not have the capability to simulate indoor climate (it just deals with it as a heat sink through steady state conduction), ECOTECT 2011(AUTODESK 2010) was used to investigate the means of indoor climate conditions for the case study. ECOTECT has built a comprehensive 3D interface over EnergyPlus v3.1 (USDOE 2009), as an architectural dynamic modelling platform has simulated indoor thermal interactions. The meteorological factors (air temperature, wet bulb temperature, relative humidity, global radiation, short-wave direct and diffuse radiations and wind speed) for all site outdoor grids were added in their cells in a comma separated Value (CSV) file extension. This allows easy editing of the climate hourly data in an Egyptian Typical Meteorological Year (ETMY2) weather data format which can be used for Egypt, (USDOE 2009). In this study, WDF was used basically as an energy plus format, EPW, and EnergyPlus converter tool, which was used for conversion after writing new hourly data in the (CSV) file.

\section{Generating Future Weather Data File (WDF)}

A numerically air Temperature map $\left(\mathrm{T}_{\mathrm{a}}\right)$ was plotted as an example of the 3D thematic maps, which was based on the morphed WDF for 2050 scenario and present day, fig.4. Climate conditions scenarios was through the weather data morphing methodology that was provided by CC World Weather Gen Tool which WDF 2020-2050-2080 e.g. WDF Of 2050, fig.5.

\begin{tabular}{|c|c|c|c|c|c|c|c|c|}
\hline 18 & Date & $\mathrm{HH}: \mathrm{MM}$ & Datasour & DryBulb & DewPoin & RelHum & $\{$ Atmos $\mathrm{Pr}$ & is ExtHorz \\
\hline 3653 & 0110612050 & $10: 00$ & "? ?*?"?" & 24.2 & 15 & 56 & 101502 & 1117 \\
\hline 3654 & 0110612050 & $11: 00$ & *?*?*?*? & 26.2 & 13.8 & 46 & 101491 & 1248 \\
\hline 3655 & 0110612050 & $12: 00$ & *?*?*?*? & 28.4 & 13.2 & 39 & 101470 & 1311 \\
\hline 3656 & 0110612050 & $13: 00$ & *?*?*?*? & 29.2 & 11.4 & 33 & 101429 & 1301 \\
\hline 3657 & 0110612050 & $14: 00$ & "?*?*?*?" & 31.2 & 11.7 & 30 & 101378 & 1220 \\
\hline 3658 & 0110612050 & $15: 00$ & "?*?*?*? & 32 & 11.3 & 28 & 101337 & 1073 \\
\hline 3659 & 0110612050 & $16: 00$ & *?*?*?*? & 31.1 & 12.1 & 31 & 101317 & 869 \\
\hline 3660 & 0110612050 & $17: 00$ & "?*?*?*? & 32.2 & 12.5 & 30 & 101306 & 624 \\
\hline
\end{tabular}

Fig.5. part of the weather data morphing (01/06/2050) contained meteorological factors e.g. dry bulb temperature, Dew point, Relative humidity, Atmospheric pressure

\section{Implications for present and future urban developments}

In a hot climate country like Egypt many planning projects have been produced and executed to cope only with population growth (Ali 2003). Particularly in Cairo, the overwhelming population growth rate did not allow the chance for full environmental studies for both the built and the natural environment, whereas buildings and open spaces have to be adequately climate responsive. Through the methodology, which visualizes the coupled outdoor-indoor climate condition, the construction market stockholders can have an idea about the whole thermal performance and energy consumption, Fig.6.

Prepare morphed EPW files for a climate change scenario

Outdoor Simulations using ENVI-met

Apply coupling methodology and compile new EPW file using weather file converter

Study CO2, energy demand and indoor conditions using indoor simulation package

Repeat same methodology presented in fig. 1 of this paper for WDF 2020-2050-2080

Fig.6: Climate change based outdoor-indoor coupled 3-D visualization methodology modified after Fahmy (Fahmy 2010), p-175. 


\section{Conclusion and future studies}

This study has not developed a tool, but has carried out the process manually. This paper could lead to new software which enables architects and planners to realize the relationship between outdoor and indoor conditions. This methodology identifies the gaps between simulation software, and how a new system can be developed to connect these results. Therefore, comparison between different design alternatives would become possible, as will measuring thermal comfort efficiency of the urban neighbourhood.

This paper has investigated an approach of the combination between micro climate scale using ENVI-met and building scale using ECOTECT, and illustrated the importance of the interaction between outdoor - indoor thermal comfort. 3D virtual modeling supported planners, companies and civil society. Firstly, for visualizing the numerical calculation results; secondly, for developing outdoor - indoor coupling methodology, and understanding the comparison between present and future meteorological data; and thirdly, realizing the climate change conscious urban neighbourhood design.

Further research should draw attention to the prevailing wind due to the simulation for the typical summer day of the hot arid conditions in Cairo, which is noticed that the wind direction is blocked by some buildings, and consequently the canopies' air temperature increased and affected pedestrians' thermal comfort. Therefore future studies should focus on improving the spatial distribution of wind velocity by changing building shapes \& tree lines and using green roads techniques.

\section{References}

[1] Ali-Toudert, F., M. Djenane, et al. (2005). "Outdoor thermal comfort in the old desert city of Beni-Isguen, Algeria." Climate Research 28(3): 243-256.

[2] Ali-Toudert , F. and H. Mayer (2006). "Numerical study on the effects of aspect ratio and orientation of an urban street canyon on outdoor thermal comfort in hot and dry climate." Building and Environment 41(2): 94-108.

[3] Ali-Toudert, F. and H. Mayer (2007b). "Effects of asymmetry, galleries, overhanging fac, ades and vegetation on thermal comfort in urban street canyons." Solar Energy 81(6): 742-754.

[4] Ali, E. (2003). "Evaluation of the Egyptian Experiment in Establishment the new Towns in the Desert Areas." Journal of Engineering Sciences, Assiut University of Egypt 31(1).

[5] AUTODESK. (2010). "ECOTECT2011 [Available Online] http://www.autodesk.co.uk/adsk/servlet/mform?validate=no\&siteID=452932\&id=142051 63 " Retrieved 19/4/2010.

[6] Barton, H. (1995). "(1995) Sustainable Settlements: A Guide for Planners, Designers and Developers, Government Management Board, University of West of England, Bristol."

[7] CCWorldWeatherGen. (2010). "Climate Change World Weather File Generator." V1.4. Retrieved 25-5, 2010.

[8] DAMAC (2000). Hyde Park. Adobe reader. H. e. Brochure. New Cairo.

[9] Eliasson, I. (2000). "The use of climate knowledge in urban planning." Landscape and urban planning 48(1-2): 31-44.

[10]Fahmy, M. (2010a). Interactive urban form design of local climate scale in hot semi-arid zone. School of Architecture. Sheffield, University of Sheffield. PhD. 
[11]Fahmy, M. and S. Sharples (2008b). "The need for an urban climatology applied design model, [Online]. Available at: http://www.urban-climate.org/IAUC028.pdf." The online newsletter of the International Assocciation for Urban Climatology 2008(28): 15-16.

[12] Fahmy, M. and S. Sharples (2010b). "Urban form adaptation towards minimizing climate change effects in Cairo, Egypt. Accepted Manuscript." Building Services Engineering Research and Technology.

[13]Fahmy, M., A. Trabolsi, et al. (2009). Dual stage simulations to study microclimate thermal effect on comfort levels in a multi family residential building. 11th International Building Performance Simulation Association Conference University of Strathclyde in Glasgow, 27-30 July.

[14]He, J., A. Hoyano, et al. (2009). "A numerical simulation tool for predicting the impact of outdoor thermal environment on building energy performance." Applied Energy 86(9): 1596-1605.

[15]Hulme, M., X. Lu, et al. (2002). Climate change scenarios for the United Kingdom; The UKCIP02 scientific report. UK Climate Impacts Programme (UKCIP), Oxford (United Kingdom); Funded by the Department for Environment, Food and Rural Affairs. See $\mathrm{m} 02 / 35481$ for the briefing report.

[16]IPCC. (2007). "TOWARDS NEW SCENARIOS FOR ANALYSIS OF EMISSIONS, CLIMATE CHANGE, IMPACTS, AND RESPONSE STRATEGIES http://www.ipccdata.org/docs/ar5scenarios/IPCC_Final_Draft_Meeting_Report_3May08.pdf."

[17] IPCC. (2010). "HadCM3 climate scenario data download page, www.ipccdata.org/sres/hadcm3_download.html." Retrieved 25-5, 2010.

[18] Levermore, G. J. (2008). "A review of the IPCC Assessment Report Four, Part 2: Mitigation options for residential and commercial buildings." Building Service Engineering 29(4): 363-374.

[19] McEVOY, D. (2007). "Climate Change and Cities." Built Environment 33(1): 5-9.

[20]Oke, T. R. (1984). "Towards a prescription for the greater use of climatic principles in settlement planning." Energy and Buildings 7(1): 1-10.

[21] Oke, T. R. (2006). "Towards better scientific communication in urban climate." Theoretical and Applied Climatology 84(1-3): 179-190.

[22] Peng, C. and P. Blundell Jones (2004). "Reconstructing urban contexts online for interactive urban designs." Design Studies 25(2): 175-192.

[23]Radhi, H. (2009). "Evaluating the potential impact of global warming on the UAE residential buildings - A contribution to reduce the CO2 emissions." Building and Environment 44(12): 2451-2462.

[24]USDOE. (2009). "Egypt weather data [Available Online], http://apps1.eere.energy.gov/buildings/energyplus/cfm/weather_data3.cfm." Retrieved 18/7/2009.

[25]USDOE. (2009). "EnergyPlus Energy Simulation Software, [Available Online], www.apps1.eere.energy.gov/buildings/energyplus/cfm/reg_form.cfm." Retrieved 15/1/2009. 